\title{
Organizational Interventions concerning Palliation in Community Palliative Care Services: A Literature Study
}

\author{
Mette Raunkiær and Helle Timm \\ Danish Knowledge Centre for Palliative Care, Strandboulevarden 47 B, 2100 Copenhagen Ø, Denmark \\ Correspondence should be addressed to Mette Raunkiær, mr@pavi.dk
}

Received 23 March 2012; Accepted 3 May 2012

Academic Editors: K. R. Shin and T. T. Wan

Copyright ( 2012 M. Raunkiær and H. Timm. This is an open access article distributed under the Creative Commons Attribution License, which permits unrestricted use, distribution, and reproduction in any medium, provided the original work is properly cited.

Background. Studies indicate problems between different professional groups working with palliative care and the organisation of palliative home care at nursing homes. The purpose of this study is to examine international experiences and cooperative development initiatives regarding the organisation of community palliative care services. Method. The study has been carried out as a literature study based on bibliographic searches in international databases with selected key words. Results and Conclusion. The study of the literature identified 19 studies described in 20 articles that relate to development efforts and interventions regarding the organisation of palliative care in communities. Nearly, all of the studies were based on health care professionals' assessments of users (the relatives). However, it is unknown whether or how patients and relatives experience a positive effect of the interventions. The literature study shows that it is a great methodological challenge to complete and evaluate studies concerning organisation and cooperation using methods that make the results useful for others.

\section{Introduction}

After many years of focus on the development of specialised palliative efforts, attention has begun to increase, both in Denmark and internationally, on the need to develop general efforts as well, where many of them take place in communities. This development stems particularly from organisational conditions and competencies [1-3].

Studies $[4-8]$ indicate problems between different professional groups working with palliative care and the organisation of palliative home care. The challenges concern, for example, palliative care domains that necessitate specialised competencies, showing respect for the competencies of other health occupations and individuals. Other challenging issues include improved interdisciplinary collaboration and more efficient circulation of information between care settings (e.g., palliative home care teams and/or GPs, district nurses, and hospitals), improved accessibility, continuity and quality of care, and services to patients at the end of life, as well as shared GP and district nurse visits to families at home. Proactive planning from the beginning of the palliative process and clear distribution of tasks are also needed. Studies of nursing homes (NHs) $[9,10]$ also indicate problems concerning management, cooperation, communication, and shared care between professional groups.

Dying people deserve good care (also meaning good continuity of care). But the above-mentioned publications show that there are ostensibly many aspects of community palliative care services, which can be improved so that the sick and the dying and their relatives achieve comfort and continuity of care. The dying and their relatives need to be seen and treated uniquely by professionals, in other words it is essential to develop care that supports families at the centre of the effort. There is a need to improve and develop organisational structures-for example, professional guidelines and new forms of cooperation that support cooperation between the various professional groups working with community palliative care services and/or cooperation between the basic palliative level and the specialist level.

The aim of the present literature study is to examine international experiences and cooperative development initiatives regarding the organisation of community palliative care services (in other words, home care, nursing homes, and 
general medical practice). International experiences in developing competency levels in palliative care in communities have been examined in another study.

\section{Method}

This study is inspired by Polit and Becks [11] methods of how to conduct a literature study and based on bibliographic databases (Pubmed, CINAHL, and PsycInfo) and with selected keywords [11, pages 172-187]. The keywords are described in the Section 2.2. There exist different attitudes whether reviewers should limit sample to published studies or include grey literature, or restrict sample to reports in peer-reviewed journals/publications [11, pages 515-519]. In this literature study, we do not include grey literature because of access to the publications, but we do include not peerreviewed publications, otherwise the study would represent very few publications.

2.1. Inclusion and Exclusion Criteria for the Literature Search. Inclusion criteria included the following:

(i) palliation in communities, home care schemes, or nursing homes,

(ii) development initiatives in palliative care in primary health care,

(iii) palliation to adults ( $\geq 18$ years),

(iv) all diagnoses and selected diagnoses; cancer, dementia, heart and lung diseases,

(v) reviews and individual studies,

(vi) literature from the years 2000-2010,

(vii) Norwegian, Swedish, Danish, and English language literature.

Exclusion criteria included studies that target:

(i) organisation and cooperation in the secondary sector exclusively,

(ii) the specialised palliative level exclusively,

(iii) palliation to children ( $<18$ years),

(iv) non-Western material.

2.2. The Literature Search Process. The bibliographic databases PubMed/Medline, CINAHL, and PsycInfo were searched from June 2010 to October 2010.

In PubMed, there were made two searches. The first search was with the keywords "palliative care/org. \& admin OR terminal care/org. \& admin AND community health services/org. \& admin OR primary health care/org. \& admin OR community health nursing/org. \& admin OR home care services/org. \& admin OR nursing homes/org. \& admin and neoplasms OR dementia or heart diseases OR lung diseases." The second search was with the keywords "palliative care/org. \& admin OR terminal care/org. \& admin AND community health services/org. \& admin OR primary health care/org. \& admin OR community health nursing/org. \& admin OR home care services/org. \& admin OR nursing homes/org. \& admin AND interinstitutional relations OR interprofessional relations."

The search in CINAHL was based on the keywords "palliative care/org. \& admin," "terminal care/org. \& admin" with an OR as liaison combined with AND and "community health services OR primary health care AND interinstitutional relations OR interprofessional relations"; "nursing homes AND interinstitutional relations OR interprofessional relations"; "home care services AND interinstitutional relations OR interprofessional relations"; "home care services AND interinstitutional relations OR interprofessional relations."

In PsycInfo, the keywords were "palliative care," "terminal care" with OR as liaison combined with AND and "primary health care AND interprofessional relations"; primary health care AND organisation OR administration"; "nursing home AND organisation OR administration"; "nursing home AND interprofessional relations OR interinstitutional relations"; "home care services AND interinstitutional OR interprofessional relations"; "nursing AND interinstitutional OR interprofessional relations"; "nursing AND organisation OR administration."

The first screening of the publications was based on reading the abstracts (or title if no abstract existed) and in proportion to the inclusion and exclusion criteria. Afterwards, the publications were more carefully read in a fulltext version-all time in proportion to the inclusion and exclusion criteria. And at last, the articles were examined based on the analysis questions below.

2.3. Analysis Method. All included studies were analysed with respect to the following analysis questions.

(i) What country of origin is represented in the studies?

(ii) What kind of study does the publication represent?

(iii) How are the target groups and the professional actors defined?

(iv) How is the development initiative designed, including

(a) organizational units included in the development initiatives,

(b) the aim,

(c) what the development initiative is,

(d) which methods are used to evaluate the development initiative,

(e) conclusion?

\section{Results}

A total of 19 studies are included (in 20 publications). The preliminary literature search resulted in PubMed: 222 publications; CINAHL: 1397 publications; PsycInfo: 17 publications. After the first screening of the abstracts (or title if no abstract existed) and due to the inclusion and exclusion criteria, the publications were reduced to 215 publications. However, after a deep reading process in full-text versions of the publications, additional 195 publications were excluded 
due to the previously mentioned exclusion criteria above or for the following reasons: doubles, discussing and describing (i.e., personal cases, personal commentary, or experiences), focus only on symptom management, focus on problem identification and suggested interventions, focus on national and international strategies, and others such as focus on the place of death and consequences for health care policy, and focus on comparisons between patients who receive palliative care and usual care. The remaining 19 studies (20 publications) were analysed based on the analysis questions.

3.1. Country of Origin, Study Type, Target Group, and Professional Actors in the Studies. Only one publication treats development initiatives in Ireland [12], three treat development initiatives in Australia [13], and 16 publications treat development initiatives in the UK. Three studies [13-15] deal with specific patients with heart disease. The other 16 studies have either cancer patients or patient groups with nondefined diagnoses as their targets. Five studies (Table 2) have a particular focus on cooperation and organisation between GPs and/or other care groups. The other 14 studies focus on care personnel. One study is a review [16]. All other studies are individual studies and none are randomised or controlled. The evaluation method is unclear in four studies $[13,15,17,18]$.

3.2. The Development Initiatives. All studies deal with guidelines and cooperative models across various specialist and basis levels and are related to development efforts and interventions regarding palliation in the following organisation units:

(i) cooperation between basis and specialised palliative levels and/or other specialised levels,

(ii) cooperation between medical practice and other organisational units in primary health care,

(iii) palliation at nursing homes.

3.3. Development Initiatives concerning Cooperation between Basis and Specialised Palliative Levels and/or Other Specialised Levels. Seven studies described development initiatives/interventions (see Table 1). Two recent studies from the UK $[16,18]$ were concerned with pathways and guidelines referred to as The Golden Standards Framework (GSF), Liverpool Care Pathways (LCP), and Advance Cancer Care Planning (ACP). One of the studies [16] reviewed 15 documents regarding the impact of GSF and showed that GSF improves general practice processes, has a positive impact on control of symptoms, continuity, continued learning, greater understanding of palliative care supporting patients and families, and so forth. Many practices were able to implement the foundation level of the GSF. However, adoption of the higher levels of care appeared more variable. The GSF requires adequate resources. The direct impact on patients and carers is not known. The other study [18] was a model based on GSF, ACP, and LCP as a model of collaborative working. According to community matrons and nurse specialists, the model was helpful in highlighting decisions to ensure that patients and families received optimum care.
Three out of the seven earlier studies (one from Australia and two from the UK) describe development initiatives connected to palliative care of patients with noncancer diseases such as heart diseases [13-15]. The focus of these studies was on development initiatives regarding nursing care between heart specialists and the palliative specialist level. These initiatives dealt with cooperation between specialist groups such as shared visits to families at home, establishing groups for patients with heart disease, common education for specialist groups, mentorship, visits to each other's practices, and development of palliative thinking in other specialist contexts. Some of the greatest successes involved better communication between specialist groups. One study [14] included patient evaluations of being included in a support group. The intervention was assessed positively.

Two other studies from the UK are concerned with evaluation of two different initiatives: a clinical nurse specialist post [17] and a 72-hour community palliative care nursing service [19]. The evaluation of the new post involved $20 \%$ of a clinical nurse specialist's fulltime position being dedicated to working with three palliative care teams. That study concluded that the intervention made progress in improving communication and collaboration between the teams as well as improving recognition and understanding of the constraints under which the teams work. It also provided an opportunity to follow patients and trace their care plan as well as including a more detailed history of the patients' care. Evaluation of the 72-hour community palliative care nursing service was done in connection with audits and questionnaires put to health professionals. That study concluded that the outreach service provided specialist palliative care to patients as they faced the transition between in-patient specialist palliative care and the community setting, particularly providing extra support on discharge from the in-patient unit. The 72-hour service is growing and remains able to respond to patients' needs quickly with expert support.

\subsection{Development Initiatives concerning the Cooperation} between Medical Practice (GPs) and Other Organisational Units. Five studies are concerned with specific initiatives focusing on improving cooperation between GPs and other health professionals (see Table 2). Two previous studiesfrom the UK and Australia-[20, 21] were concerned with the development and evaluation of a single information sheet, which intended to improve access to clinical information for nurses and doctors providing after-hours community palliative care services and an evaluation of GPs using an out-of-hours protocol. Both development initiatives were evaluated positively.

Three recent studies [22-24] are concerned with the implementation of The Golden Standards Framework (GSF) in the UK. The positive effects of the GSF included an effective approach to a systematic and high-quality service; earlier referral of palliative care patients to district nurses; multidisciplinary team meetings that enabled knowledge sharing, discussion of problems, and keeping colleagues informed. The best functioning teams used a mixture of formal and informal meetings with a relatively nonhierarchical working style between doctors and nurses. Challenges 


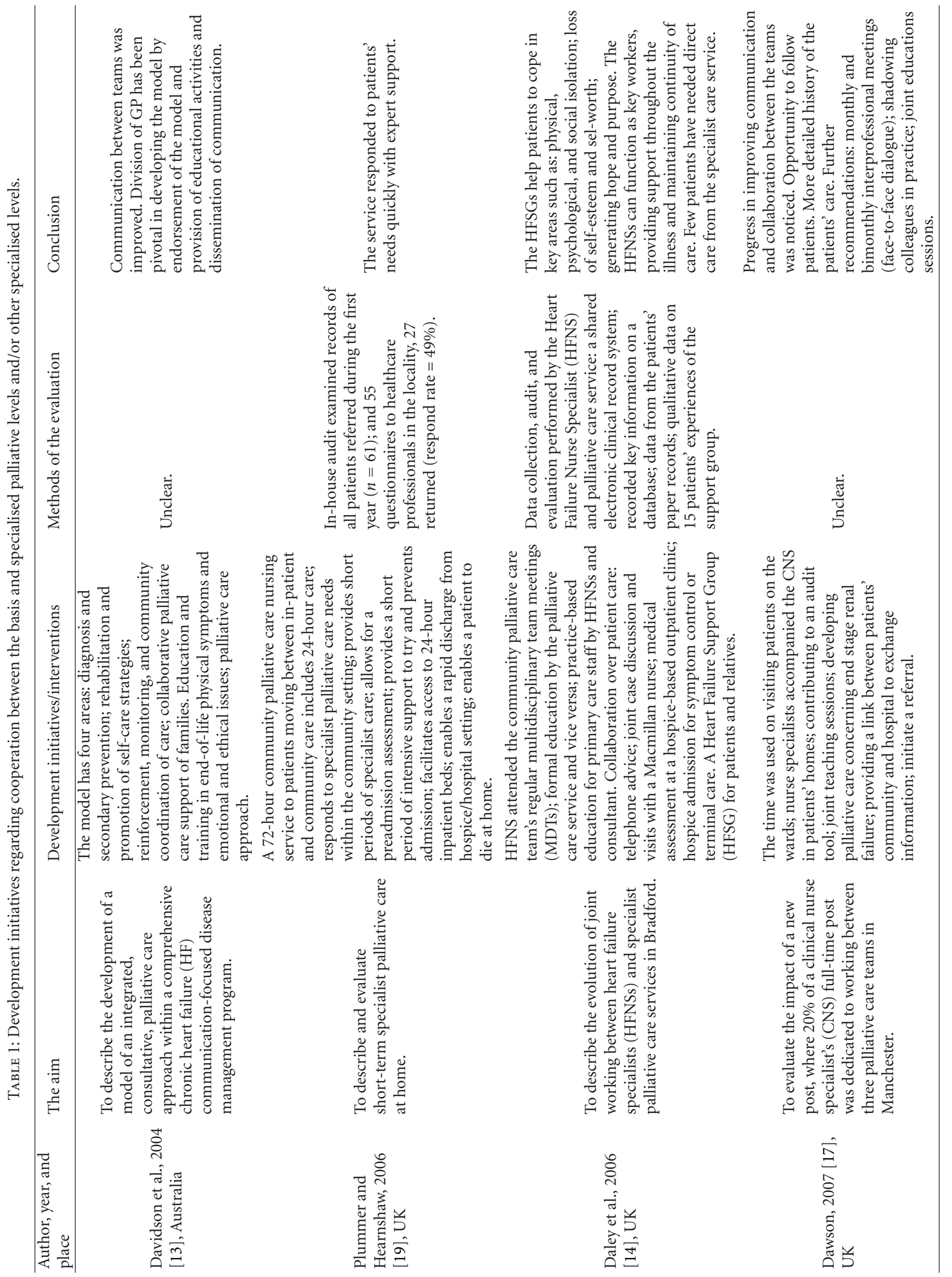




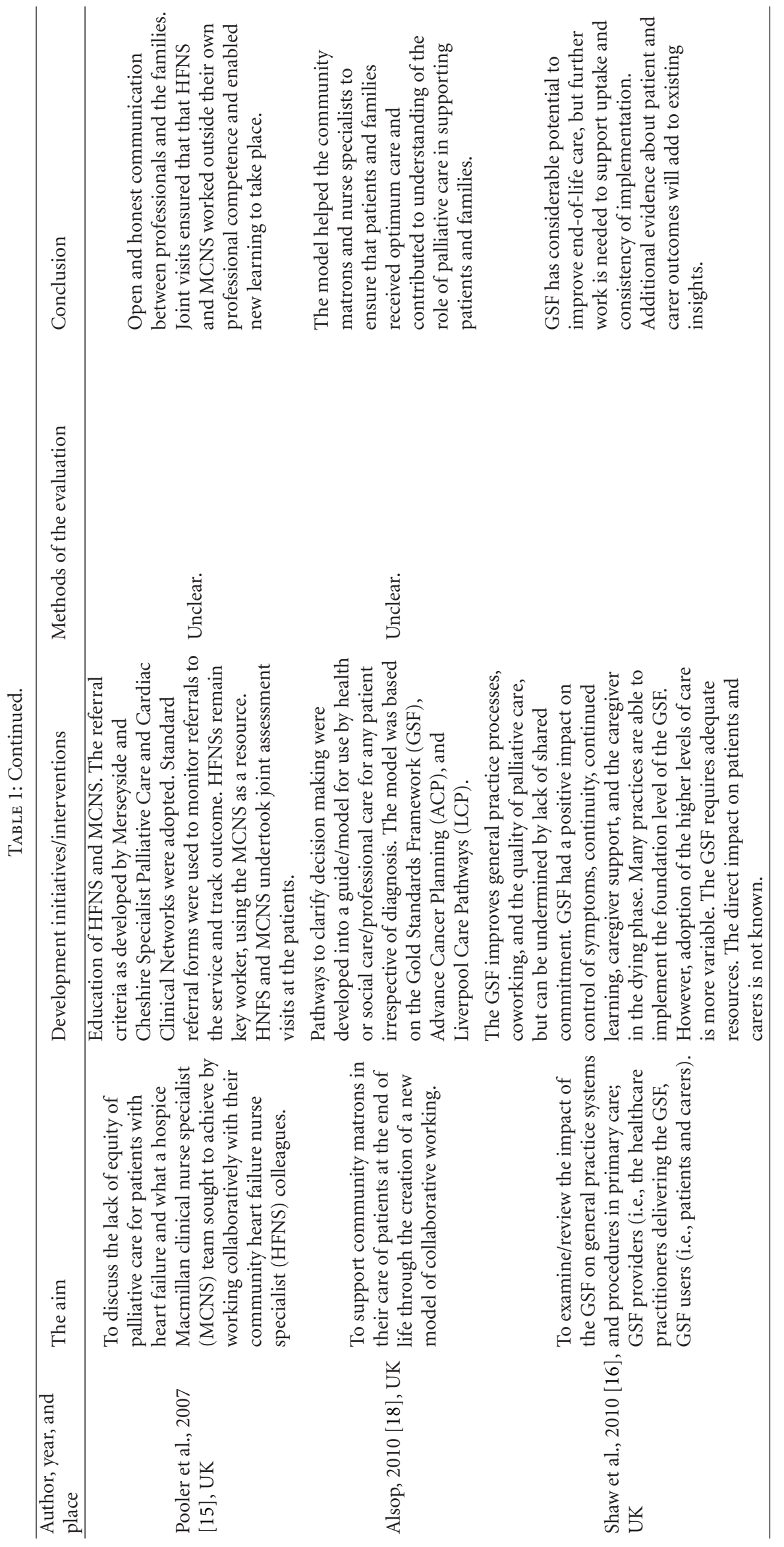




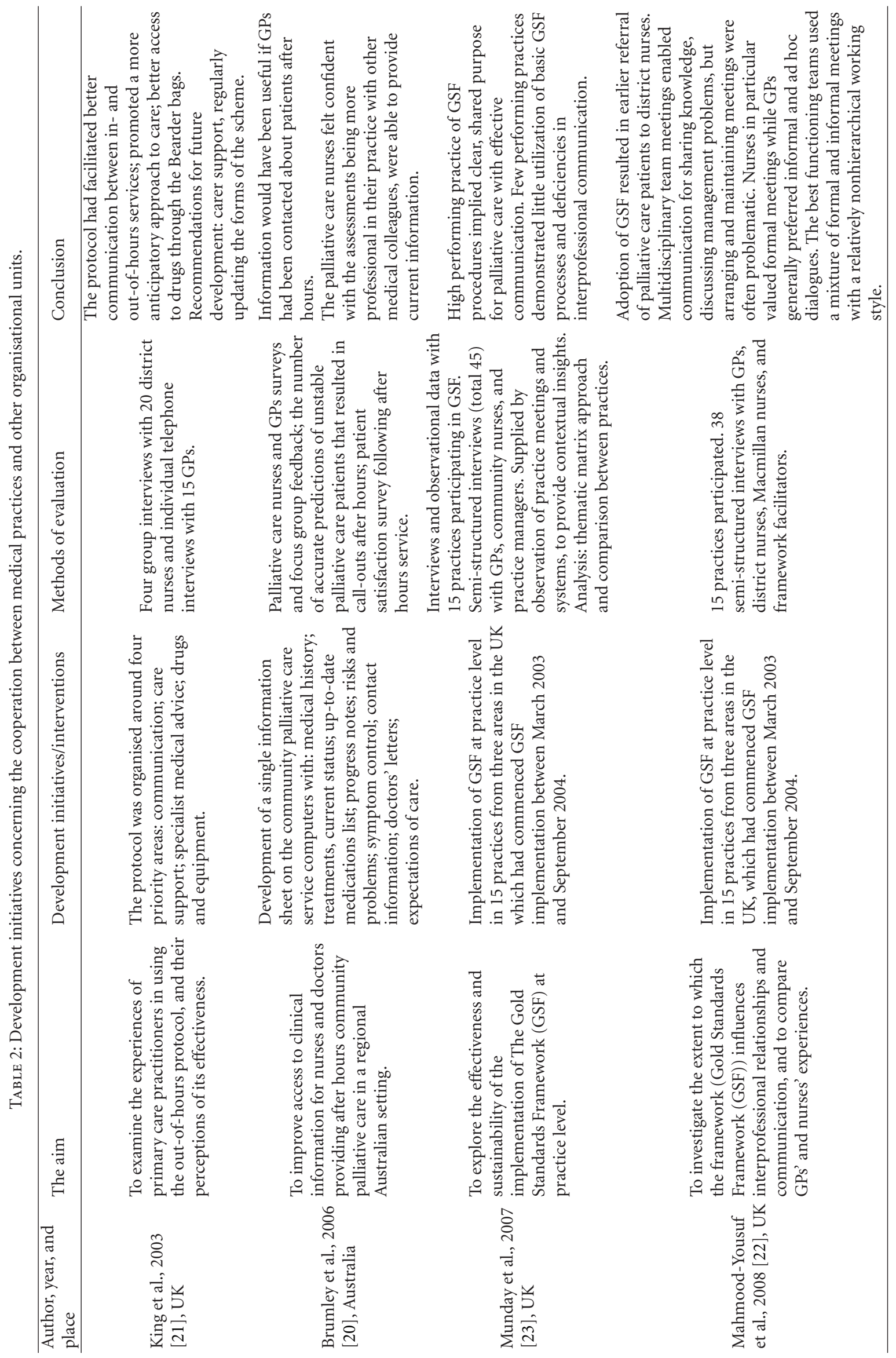




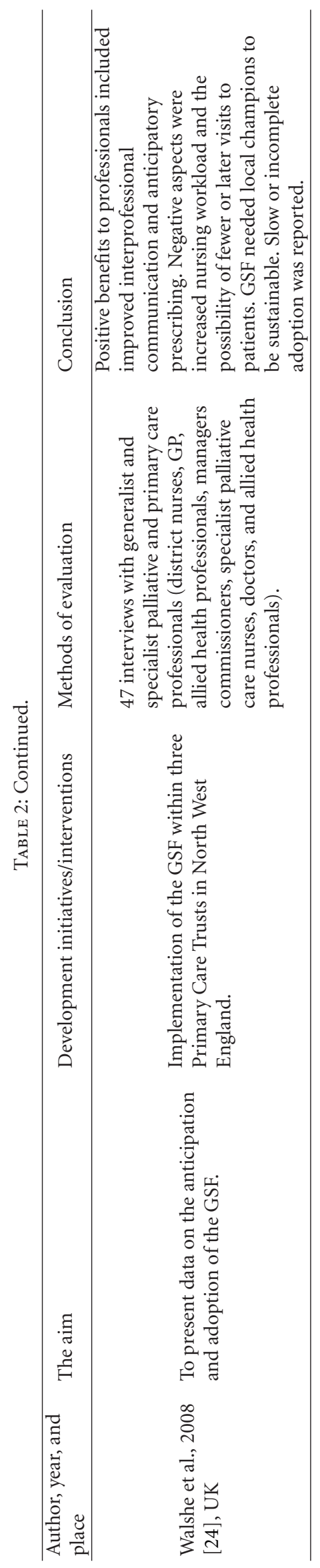


of GFS included an increased nursing workload; fewer or later visits to patients local GSF champions needed to be sustainable, and slow or incomplete adoption. The direct impact on patients and carers is not known. High performance appeared to occur when the implementation of processes promoted by GSF fitted well with the internal environment of practice.

\subsection{Development Initiatives concerning Palliation at Nursing} Homes. Eight publications and seven studies dealt with development initiatives focusing on improvements concerning palliative care at nursing homes (see Table 3 ). Two earlier studies were concerned with the implementation of specialist services in care homes. One study [12] assessed the current level of input from community-based clinical nurse specialists in palliative care into nursing homes. The assessment of this intervention showed that the main focus of interaction with the nursing homes was on pain and symptom management (physical care) often provided by telephone in connection with patients with cancer diseases. The study concluded that the clinical nurse specialists are ideally placed to provide education and support to nursing homes. The intervention of another study [25] involved the creation of a new specialist palliative nurse post in care homes. The awareness of specialist palliative care services in care homes was established in several ways. The care homes received an updated resource file palliative care service, education in palliative care for newly appointed staff in care homes, two syringe drivers were available to loan, a pain assessment tool was developed, and patients contact with specialist palliative care service was improved. These experiences, based on an unknown foundation of questionnaires and interviews, showed that the care homes felt more able to care for their patients in collaboration with clinical nurse specialists.

A study from Australia [26] examined the process of how residents' end-of-life care (EOLC) wishes were recorded to ensure that the implementation of an advance care plan (ACP) was performed according to the best available evidence. The project had four stages: $(1)+(2)$ interpretation of the five audit criteria related to involving residents (RES) and relatives (REL) in an ACP and providing them with appropriate information of EOLC issues and training the staff regarding an ACP, (3) auditing records of staff and RES, (4) getting research into practice (GRIP): situational analysis, action planning, and action taking to improve compliance with best practice. The GRIP phase showed seven barriers which included deficits related to the knowledge and education of RES, REL, and staff, as well as issues related to administration and documentation, and concerns that any implementation process would not be sustainable. RES and REL expressed a high level of satisfaction with the changes.

Five studies are concerned with the implementation of different guidelines. Two studies are concerned with implementation of the Liverpool Care Pathway (LCP). One study [27] described a pilot project to introduce LCP into care homes in the UK with a view to reducing the number of very ill elderly patients who are transferred to acute trust from care homes. The results showed that LCP had empowered the staff to talk more openly to relatives. They felt able to explain the care, but it was difficult for staff to gauge when to start the pathway. The other study [28] concerned with implementation of LCP to a 150 bed nursing home showed that LCP ensured that the patients received a high standard of palliative care and were allowed to die in the comfort and security of the place they call home. The three recent publications and two studies are concerned with the implementation of The Gold Standards Framework (GSF) in different ways. Two publications $[29,30]$ described the same study in an attempt to report the impact of implementing The Gold Standards Framework for Care Homes (GSFCH) and an adapted Liverpool Care Pathway for Care Homes (LCP) on seven private nursing homes $(\mathrm{NH})$ in the UK. The study showed that implementing GSFCH and LCP increased the use of do not attempt resuscitation documentation and noted a reduction in unnecessary hospital admissions and hospital deaths. The study also indicated that the staff changed their attitudes about dying; for example, they felt more comfortable in addressing psychosocial and emotional needs, talking to relatives and residents about dying and were more confident in recognising the different stages of the dying process. Another study [31], an evaluation of implementation of GSF in nursing homes in UK, supported the results. The evaluation was based on a pre-post survey design that showed statistically significant increases in the proportion of residents who died in the NHs and those who had an advanced care plan. Crisis admissions to hospital were also significantly reduced.

\section{Discussion}

4.1. Design and Methodology of the Studies. These studies are characterised as either being reviews or individual studies. Reviews deal with specific guidelines (GSF). One of the major current challenges in the field of heath care is to develop and promote evidence-based practice [32]. In health care science, evidence-based practice or validity is connected to controlled and preferably anonymised randomized studies. However, when the starting point is organisational development in a local context, it can be both difficult and possibly also meaningless to carry out controlled studies. It can be difficult to generalise results from one context with particular economic, organisational, professional, cultural, and possibly relational and individual conditions, to others.

The later studies appear more systematic and transparent regarding methods of intervention and assessment, while the earlier studies appear less clear in these areas. It is difficult to judge the effect of a development initiative or intervention when the evaluation designs are only described and not controlled in relation to "before and after" observations or control groups. In addition, the results of the interventions are almost completely built on the experiences of the professionals and only in a few cases, not systematically, include the judgements of patients or relatives. As a result, we do not know how these interventions change practice seen from the user's perspective.

4.2. Principal Findings. 16 out of the 19 publications dealt with studies in the UK. This is noteworthy since countries 


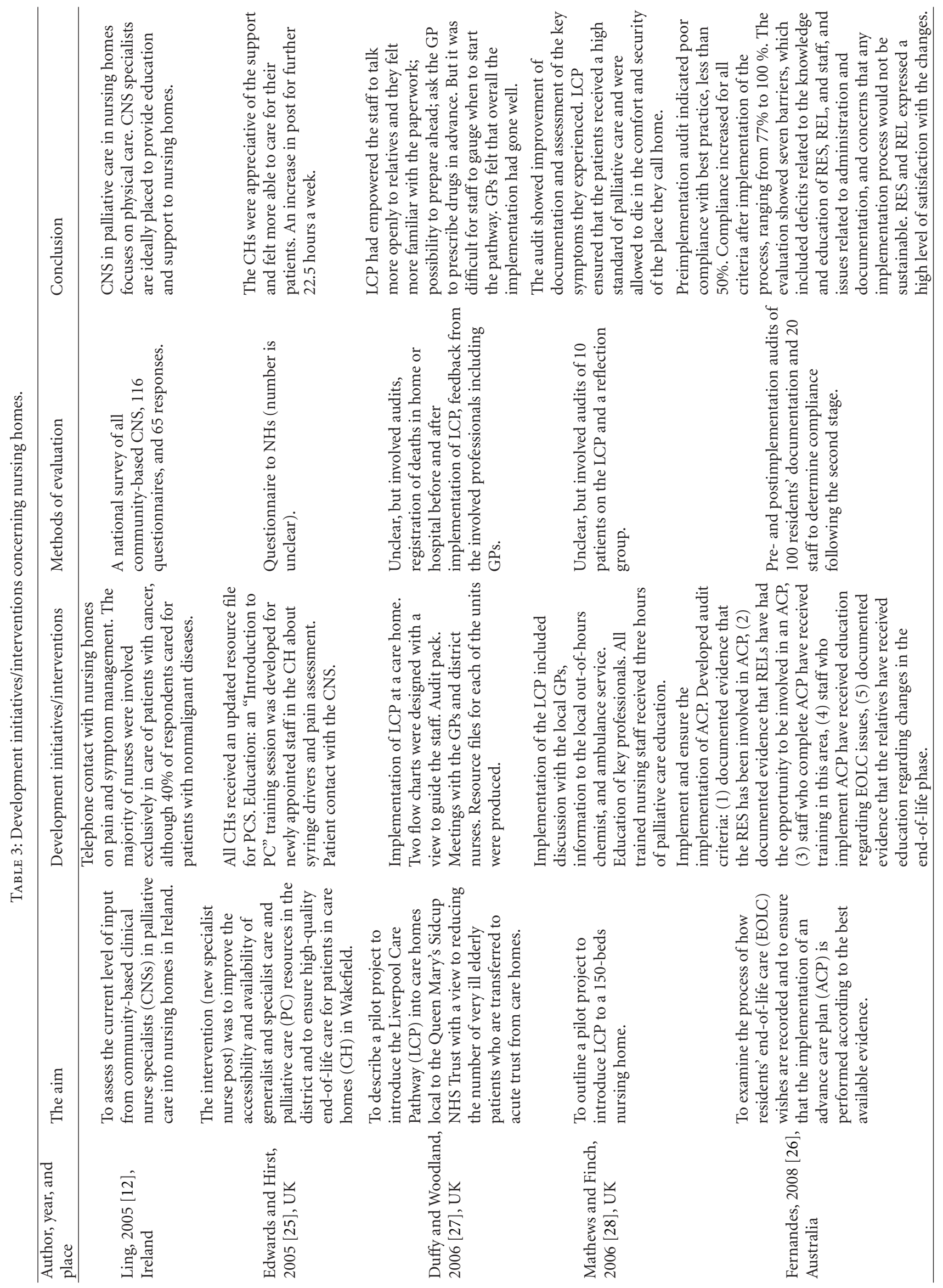




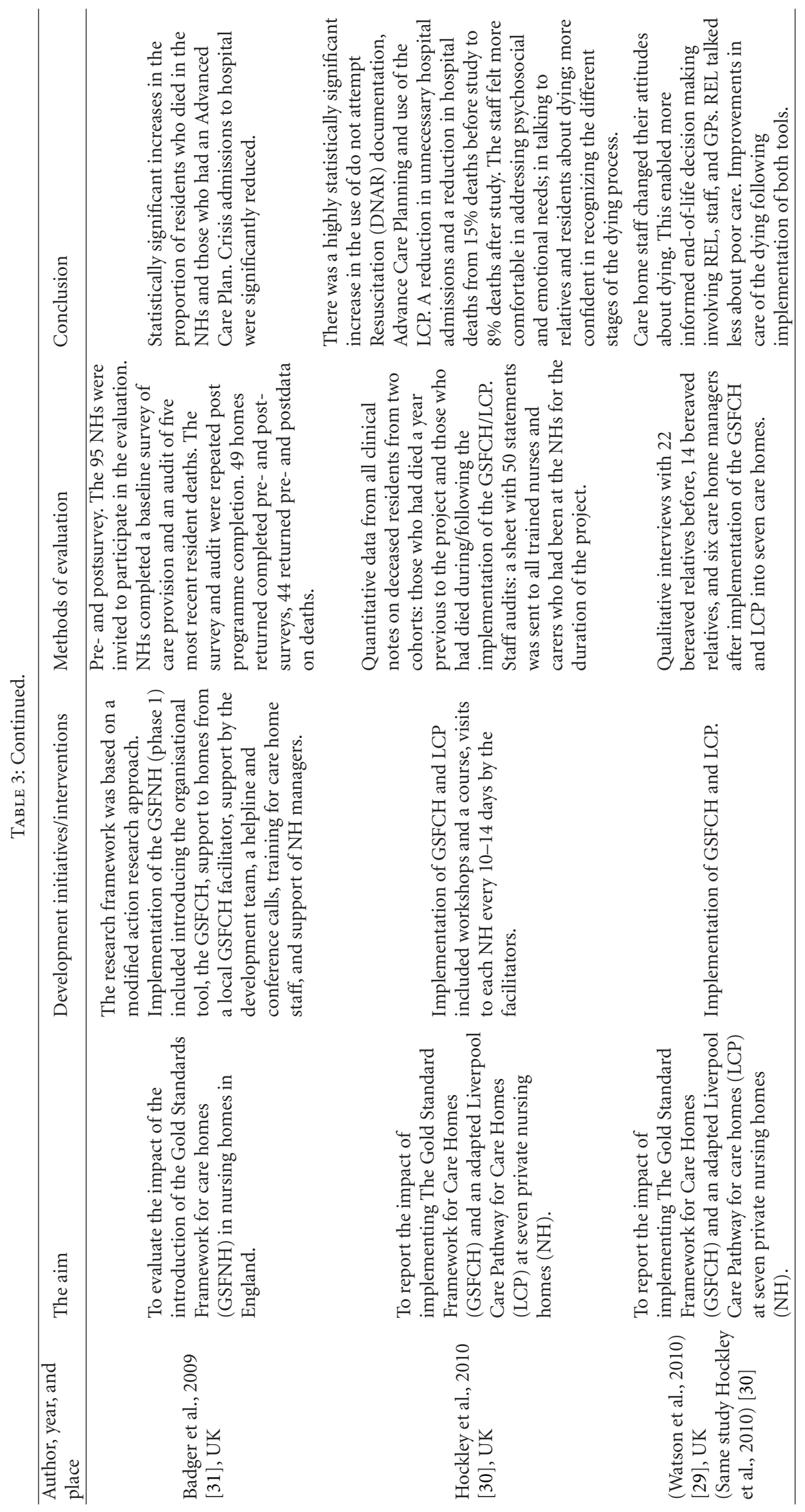


like Australia, Ireland, Norway, Sweden, and Denmark have national strategies (although different in character) for palliative efforts on the whole or in part. This can be an expression of the fact that the UK is one of the countries with the longest palliative tradition $[33,34]$, which might mean that new development initiatives are first developed and tried out in an English context and then inspire other countries. However, there is a great difference between various western countries and their welfare systems. This includes the organisation of the health care system, financing of palliative payments (percentage of own payment versus taxbased financing), education of professionals, and so forth. Therefore attempts to transfer experiences and interventions from one national context to another can be uncertain, difficult, and debatable.

The study indicates that interventions have changed character during the period from 2000 to 2010. At the start of that period, there was a particular focus on cooperative models between the basis and specialised levels of palliation, trials of diagrams attempting to improve multidisciplinary cooperation and communication regarding families (e.g., $[20,21])$, and trials of special intervention at discharge (72 hr special palliative service) [17], and so forth. In later years (e.g., $[18,30])$, the focus has been on description, implementation, and evaluation of various guidelines, most recently on The Gold Standards Framework that specifically addresses palliative care in primary health care. This might be because the UK has a well-developed structure for quality control of clinical guidelines where, since 1999, they have had one of the world's leading units, the National Institute for Health and Clinical Excellence, NICE, which is part of the National Health Care Service (NHS) [35].

The effect of the guidelines (GSF, LCP, etc.) is largely seen solely based on the assessment of professionals, which shows that implementation of guidelines has had a positive impact on multidisciplinary cooperation, communication, and so forth. Only one of the studies [29] includes users (here relatives) assessments. Experience from other studies shows that interventions do not necessarily change practice [36-38]. In other words, the implementation of guidelines alone cannot be considered a guarantee of improved practice despite positive professional assessment, unless the evaluation of development initiatives and interventions also includes the judgement of patients, residents, and relatives.

Only three publications out of 19 dealt with experiences with organisation and cooperation in relation to specific diagnostic groups-heart disease [13-15]. That might indicate that there is a need for the development of palliative efforts for other diagnostic groups such as dementia syndromes, lung disease, and so forth.

Studies show (e.g., $[4,39])$ problems with cooperation between GPs and nursing care staff in connection with palliative care when patients need care from both the primary and secondary sectors. However, only five out of 18 studies (Table 3) have a more direct focus on cooperation between GPs and nursing staff and only one study [19] addressed the connection involving the transfer of a patient between different settings. This indicates a need for development initiatives in these areas.
4.3. Strengths and Weaknesses of This Literature Study. This literature study covers only 19 studies, described in 20 publications. It could be that this is an indication that an intervention focusing on cooperation in community palliative care services is a marginal area. On the other hand, it might also be assumed that some of the development work being done is not being transmitted to academic fora. Primary community initiatives do not have a well-developed tradition for research and publication.

An expanded time period, for example, 1995-2010, and searches of several more databases might have produced more publications. In addition, non-Western studies and studies not written in one of the Scandinavian languages or English have been excluded here and might have reduced the number of studies and insights in the variation of development initiatives within community palliative basis care in non-Western countries.

The literature study is built on selected keywords. This does not exclude the possibility that the use of other key words could have led to even more relevant studies.

A secondary purpose of the study has been to include experiences from completed interventions in the primary sector. Those studies which exclusively cover problem areas, contain suggestions for interventions, or are characterised by suggestions and strategies have been excluded. That has reduced the number of publications considerably. Additionally, this literature study includes only studies which describe interventions at the basis level of palliation; in other words, studies which only focus on various types of specialist levels have been excluded. This may have reduced the number of included publications since countries have different organisations and understandings of basis and specialist palliative levels. An example with respect to Denmark and the UK is concerned with the Macmillan nurses (MN). MNs are a kind of specialist nurse in the UK, though this is not part of the Danish understanding of specialised palliative institutions (i.e., hospices and palliative teams). However, MNs are often involved in palliative processes in the primary sector in the UK as a type of specialist. This type of specialised nursing does not exist in Denmark and the palliative basis level nursing care consists solely of home care nursing. It is possible that if specialist nurses, MNs, had been defined as part of the palliative basis level in this literature study, more studies would have been included.

\section{Conclusion}

The literature study shows few and sparse studies with interventions concerning cooperative models within community palliative care services. It seems characteristic that they deal with individual studies and not controlled studies. Nearly all of the studies were based on health care professionals' assessments of users (the relatives). However, it is unknown whether or how patients and relatives feel a positive effect of the interventions. Additionally, the literature study shows that there is a lack of studies with focus on development initiatives concerning particular diagnosis groups (i.e., dementia, and KOL) cooperating with GPs and nursing personnel and the related palliative care when patients have 
needs that cross the primary and secondary sectors. Last, but not least, it is a great methodological challenge to complete and evaluate studies concerning organisation and cooperation using methods that make the results useful for others.

\section{References}

[1] Department of Health, End of Life Care Strategy: Promoting High Quality Care for All Adults at the End for Life, Department of Health, London, UK, 2008.

[2] L. Radbruch and S. Payne, "White paper on standards and norms for hospice and palliative care in Europe: part 1," European Journal of Palliative Care, vol. 16, no. 6, pp. 278-289, 2009.

[3] L. Radbruch and S. Payne, "White paper on standards and norms for hospice and palliative care in Europe: part 2," European Journal of Palliative Care, vol. 17, no. 1, pp. 22-33, 2010.

[4] M. A. Neergaard, F. Olesen, A. B. Jensen, and J. Søndergaard, "Shared care in basic level palliative home care: organizational and interpersonal challenges," Journal of Palliative Medicine, vol. 13, no. 9, pp. 1071-1077, 2010.

[5] D. Morin, L. Saint-Laurent, M. P. Bresse, C. Dallaire, and L. Fillion, "The benefits of a palliative care network: a case study in Quebec, Canada," International Journal of Palliative Nursing, vol. 13, no. 4, pp. 190-196, 2007.

[6] D. Goldschmidt, M. Groenvold, A. T. Johnsen, A. S. Stromgren, A. Krasnik, and L. Schmidt, "Cooperating with a palliative home-care team: expectations and evaluations of GPs and district nurses," Palliative Medicine, vol. 19, no. 3, pp. 241250, 2005 .

[7] K. A. Sullivan, D. McLaughlin, and F. Hasson, "Exploring district nurses'experience of a hospice at home service," International Journal of Palliative Nursing, vol. 11, no. 9, pp. 458466, 2005.

[8] H. T. Henriksen, J. Riis, and G. Leikersfeldt, "Den terminale kræftpatient i hjemmet: erfaringer fra et hospicebaseret palliativt team," Ugeskrift for Loeger, vol. 164, no. 4, article 465, 2002.

[9] M. Raunkiær and H. Timm, "Development of palliative care in nursing homes: evaluation of a Danish project," International Journal of Palliative Nursing, vol. 16, no. 12, pp. 613-620, 2010.

[10] M. Raunkiær, "Forestillinger og erfaringer om døden på plejehjem," Klinisk Sygepleje, vol. 24, no. 1, pp. 51-61, 2010.

[11] D. F. Polit and C. T. Beck, Nursing Research: Appraising Evidence for Nursing Practice, Wolters Kluwer, Philadelphia, $\mathrm{Pa}, \mathrm{USA}, 2010$.

[12] J. Ling, "Palliative care in Irish nursing homes: the work of community clinical nurse specialists," International Journal of Palliative Nursing, vol. 11, no. 7, pp. 314-321, 2005.

[13] P. M. Davidson, G. Paull, K. Introna et al., "Integrated, collaborative palliative care in heart failure: the St. George Heart Failure Service experience 1999-2002," The Journal of Cardiovascular Nursing, vol. 19, no. 1, pp. 68-75, 2004.

[14] A. Daley, C. Matthews, and A. Williams, "Heart failure and palliative care services working in partnership: report of a new model of care," Palliative Medicine, vol. 20, no. 6, pp. 593-601, 2006.

[15] J. Pooler, A. Yates, and S. Ellison, "Caring for patients dying at home from heart failure: a new way of working," International Journal of Palliative Nursing, vol. 13, no. 6, pp. 266-271, 2007.

[16] K. L. Shaw, C. Clifford, K. Thomas, and H. Meehan, "Improving end-of-life care: a critical review of the Gold Standards
Framework in primary care," Palliative Medicine, vol. 24, no. 3, pp. 317-329, 2010.

[17] S. Dawson, "Interprofessional working: communication, collaboration... perspiration!," International Journal of Palliative Nursing, vol. 13, no. 10, pp. 502-505, 2007.

[18] A. Alsop, "Collaborative working in end-of-life care: developing a guide for health and social care professionals," International Journal of Palliative Nursing, vol. 16, no. 3, pp. 120-125, 2010.

[19] S. Plummer and C. Hearnshaw, "Reviewing a new model for delivering short-term specialist palliative care at home," International Journal of Palliative Nursing, vol. 12, no. 4, pp. 183-188, 2006.

[20] D. Brumley, J. Fisher, H. Robinson, and M. Ashby, "Improving access to clinical information in after hours community palliative care," Australian Journal of Advanced Nursing, vol. 24, no. 1, pp. 27-32, 2006.

[21] N. King, K. Thomas, and D. Bell, "An out-of-hours protocol for community palliative care: practitioners'perspectives," International Journal of Palliative Nursing, vol. 9, no. 7, pp. 277-282, 2003.

[22] K. Mahmood-Yousuf, D. Munday, N. King, and J. Dale, "Interprofessional relationships and communication in primary palliative care: impact of the Gold Standards Framework," British Journal of General Practice, vol. 58, no. 549, pp. 256263, 2008.

[23] D. Munday, K. Mahmood, J. Dale, and N. King, "Facilitating good process in primary palliative care: does the Gold Standards Framework enable quality performance?" Family Practice, vol. 24, no. 5, pp. 486-494, 2007.

[24] C. Walshe, A. Caress, C. Chew-Graham, and C. Todd, "Implementation and impact of the Gold Standards Framework in community palliative care: a qualitative study of three primary care trusts," Palliative Medicine, vol. 22, no. 6, pp. 736-743, 2008.

[25] A. Edwards and P. Hirst, "Supporting palliative care in care homes: the way forward," European Journal of Palliative Care, vol. 12, no. 2, pp. 64-68, 2005.

[26] G. Fernandes, "Implementaiton of best practice in advance care planning in an "ageing in place" aged care facility," International Journal of Evidence-Based Healthcare, vol. 6, pp. 270-276, 2008.

[27] A. Duffy and C. Woodland, "Introducing the Liverpool Care Pathway into nursing homes," Nursing Older People, vol. 18, no. 9, pp. 33-36, 2006.

[28] K. Mathews and J. Finch, "Using the Liverpool Care Pathway in a nursing home," Nursing Times, vol. 102, no. 37, pp. 34-35, 2006.

[29] J. Watson, J. Hockley, and S. A. Murray, "Evaluating effectiveness of the CSFCH and LCP in care homes," End of Life Care, vol. 4, no. 3, pp. 42-49, 2010.

[30] J. Hockley, J. Watson, D. Oxenham, and S. A. Murray, "The integrated implementation of two end-of-life care tools in nursing care homes in the UK: an in-depth evaluation," Palliative Medicine, vol. 24, no. 8, pp. 828-838, 2010.

[31] F. Badger, C. Clifford, A. Hewison, and K. Thomas, "An evaluation of the implementation of a programme to improve end-of-life care in nursing homes," Palliative Medicine, vol. 23, no. 6, pp. 502-511, 2009.

[32] E. Mattila, K. Leino, E. Paavilainen, and P. Aastedt-Kurki, "Nursing intervention studies on patients and family members: a systematic literature review," Scandinavian Journal of Caring Sciences, vol. 23, no. 3, pp. 611-622, 2009. 
[33] J. Hockley and D. Clark, Eds., Palliative Care for Older People in Care Homes, Open University Press, Buckingham, UK, 2008.

[34] J. M. Addington-Hall and I. J. Higginson, Eds., Palliative Care for Non-Cancer Patients, Oxford University Press, Oxford, UK, 2005.

[35] http://www.nice.org.uk/.

[36] U. M. Emilsson, "Identity and relationships: on understanding social work with older people suffering from dementia," Journal of Social Work Practice, vol. 22, no. 3, pp. 317-328, 2008.

[37] U. M. Emilsson, "Supervision as pedagogy and support in the Swedish eldercare- a developmental project," Journal of Gerontological Social Work, vol. 47, no. 3-4, pp. 83-102, 2006.

[38] M. U. Emilsson, Handledning och lärande $i$ äldreomsorgens vardag, Studentlitteratur, Lund, Sweden, 2004.

[39] D. Goldschmidt, Evaluation of palliative home care: views of patients, carers, general practitioners and district nurses [Ph.D. thesis], Department of Social Medicine \& Department of Health Services Research, Insitute of Public Health, University of Copenhagen, Copenhagen, Denmark, 2006. 


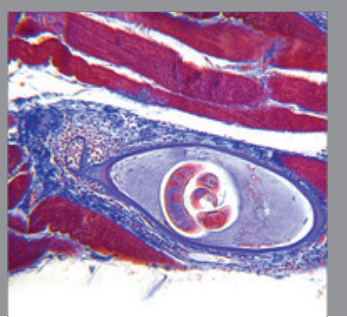

Gastroenterology

Research and Practice
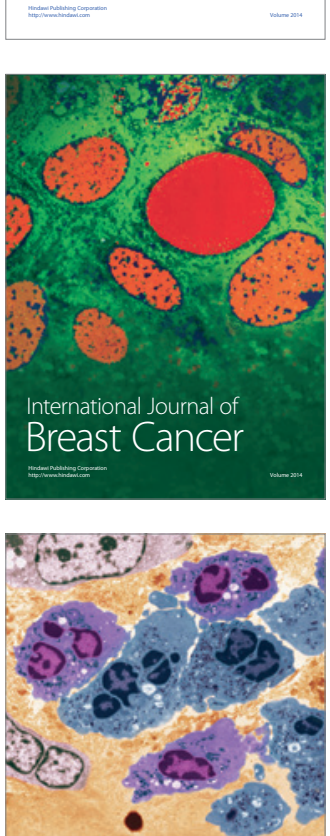

International Journal of Inflammation
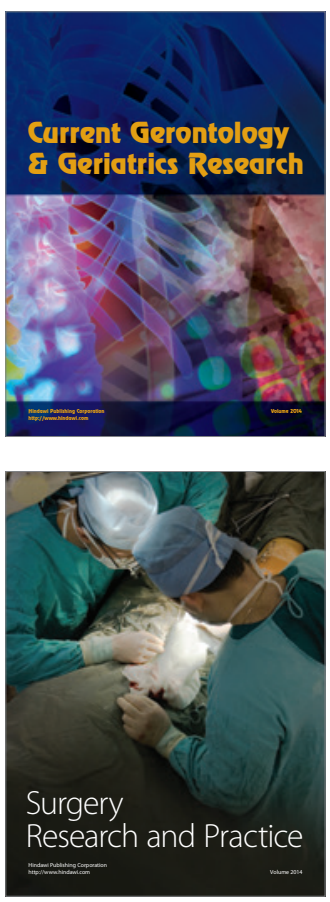
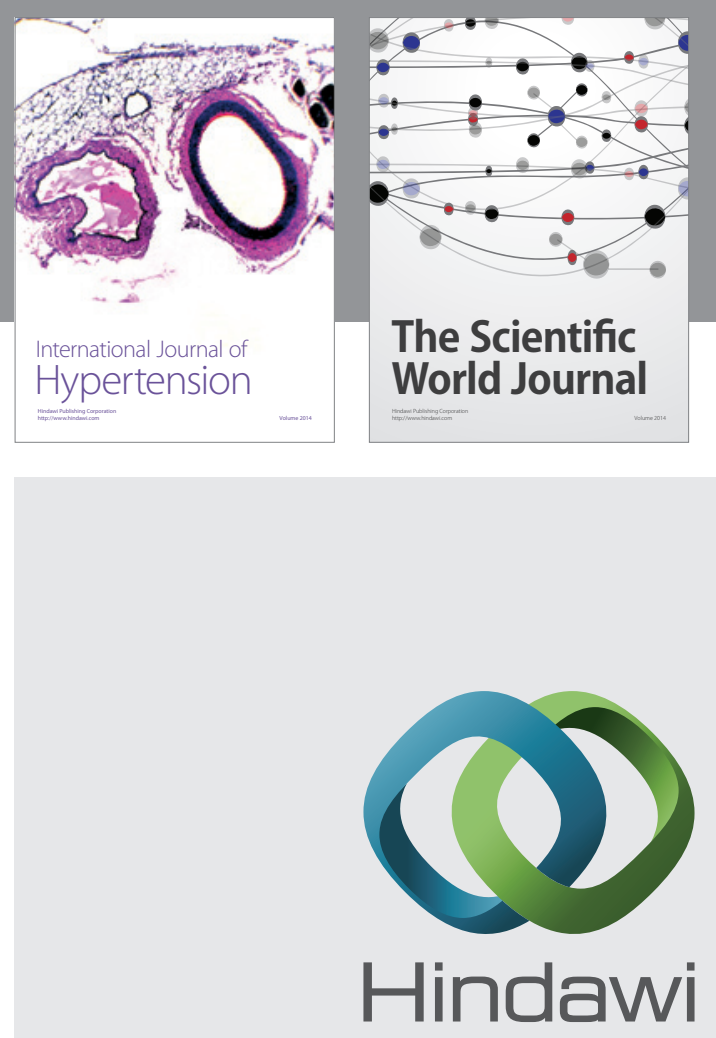

Submit your manuscripts at

http://www.hindawi.com
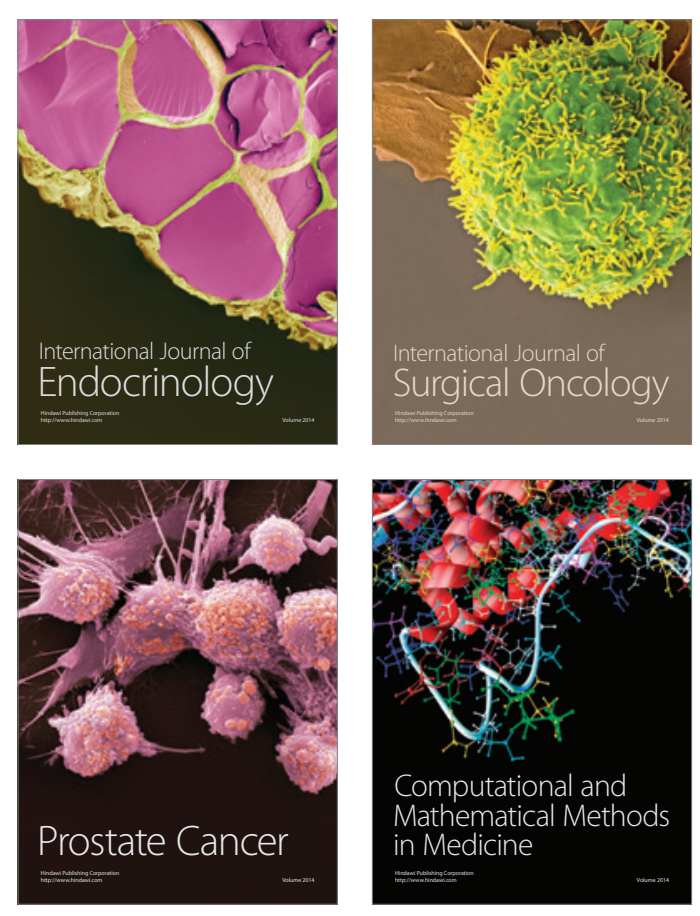
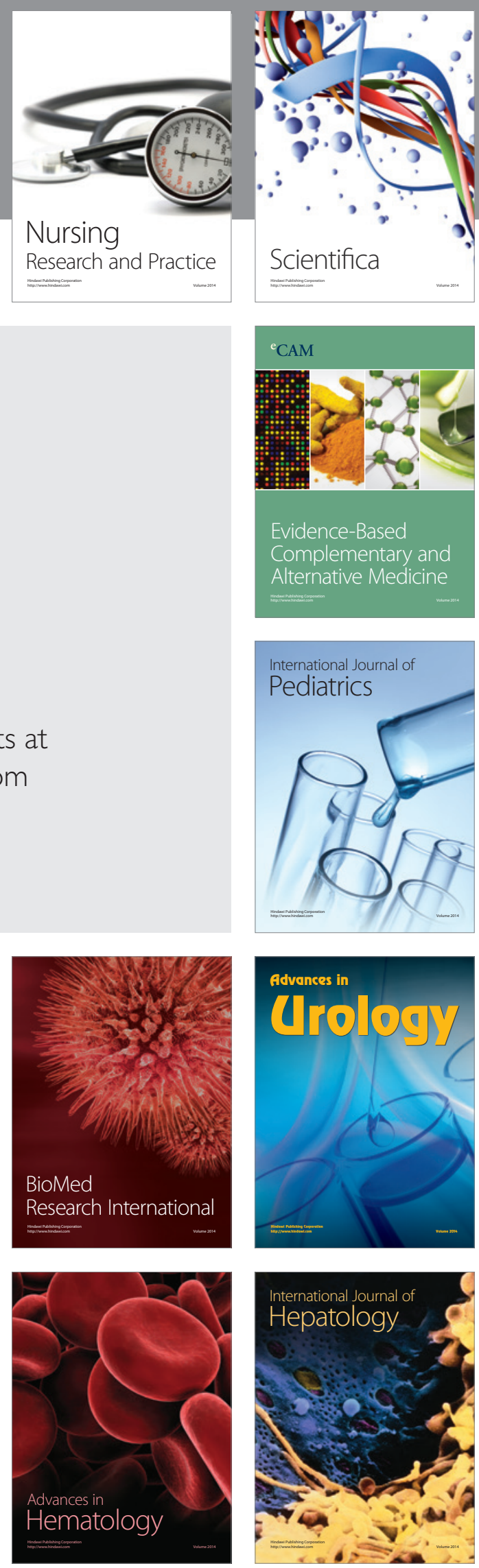